\title{
MENTAL HEALTH IN THE PANDEMIC TIMES
}

\author{
MONIKA FRĄCKOWIAK-SOCHAŃSKA ${ }^{1}$ \\ ${ }^{1}$ Adam Mickiewicz University in Poznań, Szamarzewskiego 89 C, 60-568 Poznań, Poland. ORCID: 0000- \\ 0002-8318-5295,Email: monikafs@amu.edu.pl
}

\begin{abstract}
The primary aim of this paper is an attempt at the analysis of the prospective direct and indirect, short- and long-term consequences of COVID-19 pandemic for the individuals' mental health. The secondary aim is to deconstruct the binarity of categories of "mental health" and "mental disorder" in the context of the global critical situation. The pandemic and its consequences such as isolation requirements as well as uncertainty in diverse aspects of life burden the individuals with the stress that results in the increase of anxiety and depressiveness, which challenges the public mental health care systems. Since the anxiety and depressive states are the reactions to a hazardous outside situation, the categories of "mental health" and "mental disorder" needs reconsideration. The theoretical framework of present analyses is determined by the theory of social (cultural) trauma. The method used for the present study is a meta-analysis of theoretical literature, the results of empirical research on COVID-19 pandemic published so far (mostly in medical journals), studies on psychosocial aspects of the previous pandemics (SARS and Ebola), and press publications selected on the basis of their content on mental health issues in the context of the coronavirus pandemic.
\end{abstract}

KEYWORDS: pandemic, social trauma, stress, mental health, mental disorders, deconstruction 


\section{INTRODUCTION}

The primary aim of this paper is an attempt at the analysis of the prospective direct and indirect, short- and long-term consequences of COVID-19 pandemic for the individuals' mental health. The secondary aim is to deconstruct the binarity of categories of 'mental health' and 'mental disorder' in the context of the global critical situation. The theoretical framework of present analyses is determined by the theory of social (cultural) trauma (Alexander, Eyerman et al. 2004). I am especially interested in the individual's biography level of social trauma. The method used for the present study is a meta-analysis of theoretical literature, the results of empirical research on COVID-19 pandemic published so far (mostly in medical journals), studies on psychosocial aspects of the previous pandemics (SARS and Ebola), and press publications selected on the basis of their content on mental health issues in the context of the coronavirus pandemic.

Mental health is one of the officially acknowledged world public health issues for at least two decades (WHO 2001). The WHO's data according to which one fourth to one-third of today's world population experiences mental states that meet formal criteria of psychiatric disorders, among who at least 264000000 people around the world are affected by depression (WHO 2020) and 1 in 13 globally suffers from anxiety disorders (ADDA 2020), give a picture of the world population's mental health before the COVID-19 epidemic. The state of the pandemic and its consequences (likewise any social crisis) is a source of massive stress that burdens the individuals and impact their mental condition (Dong and Bouey 2020). The awareness of danger may activate anxiety based on the primary fear in the face of direct or anticipated life hazard. Besides, the on-going regulatory changes, social isolation and the pandemic's consequence for the labor market heighten the existential fear in the face of an unknown future. In this context, we can foresee that the number of people facing stress-related mental health problems will grow. Since the states that meet the formal criteria of mental disorders are the responses to outside conditions that are interpreted as dangerous (and they are really so) we can reasonably question the binarity of the categories of 'mental health' and 'mental disease' or 'disorder'. Taking into consideration the increase in the mental health problems among representatives of today's societies along with the official social distancing requirements, the mental health care systems will have to face a growing number of challenges. The pandemic is already perceived as a game-changer for mental health care systems (Basu 2020).

\section{COVID-19 PANDEMIC AS SOCIAL AND INDIVIDUAL TRAUMA}

As Jeffrey C. Alexander writes "Cultural trauma occurs when members of a collectivity feel they have been subjected to a horrendous event that leaves indelible marks upon their group consciousness, marking their memories forever and changing their future identity in fundamental and irrevocable ways" (2004:1). Since we are not able to foresee at this moment, how long-lasting the consequences for the social identity of representatives of today's global and local communities will be, we will focus towards the relations between the collective and individual levels of social (cultural) trauma. 
The COVID-19 pandemic meets the criteria of social trauma in the sense that it leads to rapid, unexpected, often radical changes in diverse areas of social life (such as economy and politics as well as individuals' everyday life). These changes manifest themselves in altering the systemic regulations as well as the rules of everyday routine and the priorities declared at the social and the personal level. Our world of habits, customs and meanings, stable so far, gets disturbed. The new forms of risk emerge, since everyday activities such as interacting with other people in regular social situations became hazardous. The economic consequences of pandemic lead to job losses, worsening the conditions of living, and feeling of uncertainty for growing number of people. In this context the problem of inequalities in the distribution of resources that enable the individuals to protect themselves occurs. Moreover, social trauma causes the new perception of pre-existing problems such as for example not enough resources in health care and other institutions that have crucial meaning in the critical situations. Finally, social trauma leads to the revision of the ways the key values, norms and notions that constitute the culture are conceptualized (Sztompka 2002: 463). In the context of life hazard the individuals change their frames of references in which they define their priorities and interpret phenomena.

A state of pandemic creates the environment conducive for conspiracy theories, moral panics and scapegoating. In this context, some secondary traumatizing events may take place. The example of them is the discriminatory commentary and harmful stereotyping aimed at people of Chinese and other Asian descent in the USA whose public image swings from 'the model minority' to "the perpetual foreigners who pose a threat to stability and order" (Lee 2020). As Mathew Lee writes "During disease outbreaks, attacks on marginalized groups are not an exception, but the norm. This racism and xenophobia are additionally stoked by discourse that casts the bodies and behaviors of Chinese Americans and other Asian Americans as suspicious and even at fault for spreading disease. While viruses and other pathogens do not discriminate between hosts based on race, ethnicity, nationality or immigration status - stigma and misinformation certainly do" (2020). Examples of this can be found throughout history. Jewish communities in Europe were targeted during the bubonic plague in the 1300s, Irish immigrants in the USA were blamed for typhoid in the 1800s, Haitian Americans were thought to be responsible for HIV in the 1980s, Mexican Americans for swine flu in 2009, and West Africans for Ebola in 2014. In 1906, a Chinatown in Orange County was torched and burned down while city officials did not prevent this act of hostility, citing disease (leprosy) and threats to public health as the justification. Chinese Americans also aroused ire for SARS in 2003, and again today, for COVID-19 (Lee 2020).

One of the emblematic mechanisms in the process of coping with social trauma is introducing the strategies that are supposed to reinstate individuals' safety on one level but deprive them of safety on the other level. The social isolation required nowadays in most countries struggling with the pandemic intends to prevent spreading the virus but it may may have some side effects for people's mental condition. In this context, a problem of domestic violence and gender-based violence has to be discussed. As the WHO notes gender-based violence tends to increase during humanitarian 
emergencies and conflicts (WHO 2005). Reports from China suggest the coronavirus has already caused a significant spike in domestic violence. Local police stations noted a threefold increase in cases reported in February 2020 compared with the previous year (Mahdawi 2020). Wan Fei, the founder of an anti-domestic violence not-profit in China claims that according to the organization's statistics, 90\% of the causes of violence in the recent two months are related to the COVID-19 epidemic (Mahdawi 2020). Similar scenarios take place throughout the world. According to an exemplary American domestic violence hotline (in Portland, Oregon), between March 9 and March 15, the number of calls doubled comparing to the previous weeks and months (Mahdawi 2020). There has been reported that the US national domestic violence hotline is hearing from a growing number of callers whose abusers are using COVID-19 to further control and isolate them. The cases of withholding financial resources or medical assistance by the perpetrators have been reported as well as threatening to throw the victims out on the street so they get sick (Mahdawi 2020).

According to economic prognoses one of the consequences of the pandemic is global employment crisis ${ }^{1}$, the effects of which are already being felt by individuals who have been made redundant or have had to suspend their businesses. On the bases of the data on the impact of the economic crisis on mental health, we can foresee that as the consequences of unemployment there will be an increase of mental health problems such as depression, substance abuse, addictions, and suicidal attempts. In the classic study, Marvin Harvey Brenner analyzed psychiatric hospital admission statistics and unemployment data in New York from 1841 to 1968 and noted that psychiatric hospitalization rates increase during the periods of economic recession and rising unemployment. Brenner puts forward the thesis that the inability to fulfill certain social roles (employee and breadwinner) along with the uncertainty in the period of economic depression escalates the experience of stress and intensifies the individuals' life crises. In these conditions certain mental disorders are more likely to emerge or manifest themselves. In this context, diverse dimensions of social inequalities emerge. The individuals with less material, social and cultural capital (poorly educated, without sufficient material resources, with poor social support and weaker problem-solving skills) are particularly vulnerable to the destructive consequences of stress related to socioeconomic crises. Exactly the same conclusions have been confirmed in the WHO's study on the impact of the world economic crisis in 2008 on the mental health of representatives of XXI century societies (WHO 2011). Recession and unemployment result in the increase of poverty of the households, which indirectly lead to the increase of the suicidal rates, addictions and deaths due to alcohol abuse as well as the incidence of depression (WHO 2011). The most vulnerable individuals are those of low incomes and education level, working in occupations of a particularly high risk of losing employment, monoparental families, children and adolescents, representatives of ethnic minorities, immigrants and the elders (WHO 2011, 2014). The vulnerability

\footnotetext{
${ }^{1}$ Within one week in March 2020 unemployment insurance claims in the US soared past three million, a record-breaking number which far surpasses previous highs. To put it in context, this figure shatters the Great Recession crest of 665,000 of March 2009 and the previous record high of 695,000 in 1982, when the US Federal Reserve tried to tame inflation through its monetary policy (Fowler 2020).
} 
to mental health problems is related to factors such as lack of safety, feeling of hopelessness and insufficient social, cultural and material resources. Health in general and mental health, in particular, can be though interpreted as a social good and 'capital for the hard times', access to which is distributed unequally. The resources that help to protect mental health depend on the state's social policy that can mitigate the effects of the crisis. The relations between mental health and social policy are illustrated by a comparative analysis of suicide rates in Sweden and Spain from 1980 to 2005. In the early 1990s, Sweden underwent a severe bank crisis, resulting in a very rapid rise in unemployment, but suicide rates were unaffected, falling steadily over this period. This contrasts with the situation in Spain, with multiple banking crises in the 1970s and 1980s. "As unemployment rates rose, suicide rates increased; when unemployment fell, suicide rates fell too. Although there are many differences between Sweden and Spain, one argument is that a major differentiating factor was the extent to which resources were budgeted for social protection, such as family support, unemployment benefits, and health care services" (WHO 2011:10). According to WHO, the average association observed in EU countries for a 1\% rise in the unemployment rate is a $0.8 \%$ rise in the suicide rate. In EU countries, each additional US\$100 per person spent on active labor market programs per year reduced the effect of a $1 \%$ rise in the unemployment rate on the suicide rate by 0.4 percentage points. Moreover, each US\$ 100 per person spent on family support programs reduced the effect of unemployment on the suicide rate by 0.2 percentage points (WHO 2011:11). These data should be a sufficient argument in favor of investing in mental health care systems in order to prevent the destructive impact of social crises on individuals' mental health.

\section{THE PROCESS OF ADAPTATION TO THE CRITICAL SITUATION AND ITS CONSEQUENCES OF INDIVIDUALS' MENTAL HEALTH}

The situation of the pandemic undeniably burdens the global population with stress, the consequences of which are: heightening the anxiety to the extent that meet formal criteria of anxiety disorders, an increase of depressiveness (as the consequences of chronic anxiety and social isolation), difficulties in controlling one's anger and other emotions (resulting from the frustration of various needs that cannot be fulfilled due to the restrictions). The critical experiences such as being hospitalized with no family present and not being able to accompany the loved ones, dying alone or the consciousness that a loved one had died alone will lead to the mass experience of grief accompanied by PTSD and depression. From a psychological perspective, this is a life-changing experience for those who survived. Some of those who witness this via media can experience indirect grief (Pinnock 2017) and develop the vicarious trauma syndrome (Jenkins and Baird 2002). Some mass behaviors and psychosocial mechanisms described from the perspective of social psychology may strengthen the anxiety. One of these mechanisms is an overabundance of (mis)information on social media and elsewhere labeled as 'infodemic' (WHO 2019; Dong and Bouey 2020).

The reconstruction of the process of coping with the critical situation on the social scale focuses on the collectively repeated behaviors that can be interpreted by using a 
metaphor taken from the classical Selye’s stress theory (Łoza 2020). According to this concept, there are three stages of the general adaptation syndrome (GAS) to the stressing, critical situation: (1) the alarm reaction, (2) the stage of resistance (adaptation) and (3) the stage of exhaustion (Selye 1976). Observing the representatives' of Polish society reactions to COVID-19 epidemic chief of the Polish Neuropsychiatry Association, Bartosz Łoza claims that the alarm reaction boiled down to rapid actions in the face of unexpected information perceived as threatening, the examples of which were making supplies compulsively, withdrawing cash, etc. The second stage boils down to the adaptation to an ongoing stressful situation. The purpose of individuals' behaviors in this stage is to normalize the emotionally aggravating situations and to reduce the tension. People become more active in social media so that they can compensate for the social isolation "offline", send funny memes, exchange ideas, how to spend time at home, recommend each other the free online events, offer altruistic help. In one of the viral movies spread in social media, there is a symbolic scene picturing the residents of Italian cities singing together on the balconies. This kind of behavior aims at abreacting and it is a part of strategies of risk and uncertainty management. The adaptation stage will last until the cause of stress disappears or as long as we have enough internal resources. The longer this phase lasts, the more weakened our resources are, until the stage of exhaustion begins. Then, as in the alarm stage, all types of reactions are possible again as well pro-social as anti-social. In this context with all types of anxiety disorders are likely to increase. This applies even to 30 percent of the population (Łoza 2020; Moskalewicz, Kiejna and Wojtyniak 2012; WHO 2020). Besides we can predict the occurrence of the other consequences of stress such as depressive states accompanied by symptoms of discouragement, resignation, lack of energy, burnout, but also rebellion, struggle, disorganization and escape behaviors. People suffering from psychotic disorders may experience the worsening of their condition and the psychotic relapses resulting from increased stress (Łoza 2020).

The difference in the pandemic threat experienced by the representatives of diverse age groups may cause tensions in intergenerational and family relations. The teenagers may feel frustration and anger because of their freedom's limitations since the perspective of hazard is not entirely realistic for them. The elderly people are in the real crisis as they are aware of deadly danger. The young people usually do not have symptoms of COVID-19 infection if they catch the virus, but as the carriers, they spread it away, whereas the elderly get ill most seriously. It can even be a modus operandi of this virus - the young spread it and the older get sick (Łoza 2020). The elderly people face a serious crisis and at the same time, many of them need assistance from the younger members of families. The intergenerational differences in the face of not equally distributed hazard can expose families to a crisis.

Another high-risk group is health care workers, especially those on the front line who are directly involved in the diagnosis, treatment, and care of patients with COVID-19. Due to the critical situation, they face directly on daily bases, they are at risk of developing high psychological distress and other mental health symptoms. "The ever-increasing number of confirmed and suspected cases, overwhelming workload, depletion of personal protection equipment, widespread media coverage, lack of specific 
drugs, and feelings of being inadequately supported may all contribute to the mental burden of these health care workers" (Lai, Ma, Wang et al. 2020:2). According to the cross-sectional survey study on the cluster sample $(\mathrm{N}=1257)$ of health care workers in 34 hospitals in Wuhan, China and other regions inside and outside Hubei province, carried out between January 29 and February 3, 2020, a considerable proportion of the participants had symptoms of distress (71,5\%), depression (50,4\%), anxiety (44,6\%), and insomnia (34\%). The cited study shows that nurses, women, frontline health care workers, and those working in Wuhan, reported more severe degrees of all measurements of mental health symptoms than other health care workers (Lai, Ma, Wang, et al. 2020:1-2). Previous studies carried out after the 2002-2004 SARS outbreak have reported psychological reactions among health care workers such as fear of contagion and infection of their family, friends, and colleagues, feeling of uncertainty and stigmatization, reluctance to work or contemplating resignation, high levels of stress, anxiety, and depression symptoms, which could have long-term psychological implications (Lai, Ma, Wang et al. 2020; Maunder, Hunter, Vincent et al. 2003; Bai, Lin, Lin et al. 2004; Lee, Wong and McAlonan 2007; Chua, Cheung and Cheung 2004).

Studies on SARS 2002-2004 epidemic survivors show that the individuals who have experienced public health emergencies still have varying degrees of stress disorders, even after the event is over (Lee, Wong and McAlonan 2007; Mak, Chu, Pan et al. 2009). Therefore we can foresee the long term consequences of the COVID-19 pandemic for the populations' mental health. In this context, the (rhetorical) question arises - is the mental health care system prepared for this?

\section{THE SYSTEM OF MENTAL HEALTH CARE IN THE FACE OF CHALLENGE}

In the context of the economic crisis, many countries are facing pressure to reduce health and welfare budgets. Despite the increased need, mental health is a vulnerable target of these cuts, as it usually lacks a strong advocacy base to oppose them, unlike physical illnesses (WHO 2011:13). On the basis of the observation of mental health problems that occurred in the populations affected by epidemics od SARS in 2002-2004 and Ebola in 2014 and the current experiences with COVID-19 we can put forward a thesis that public mental health interventions should be formally integrated into public health preparedness and emergency response plans (Person, Holton and Govert 2004; Shultz, Cooper, Baingana et al. 2016; Dong and Bouey 2020). Nonetheless, the public mental healthcare system does not have sufficient reserves to operate efficiently during a crisis.

The coronavirus pandemic is perceived as a game-changer for mental healthcare. The companies offering teletherapy platforms (Talkspace) and mental health apps (Headspace and Sanvello) have noted a tremendous increase of use within the last two months, which serves their economic interests (Basu 2020). The changes in regulations due to (February and March 2020) pandemic have contributed to the development of the teletherapeutic services market. In this case, the requirement of social distancing has a key role. Besides there are some additional changes that make it easier for people to access mental health care online. For example, the US Department of 
Health and Human Services relaxed constraints that had previously made it nearly impossible to meet digitally with a doctor because of privacy concerns. Due to economic conditions that could be a permanent change, even once the current pandemic has subsided (Basu 2020). In this context, a question about the effectiveness of the teletherapy arises. Research on this issue found that patients suffering from depression who received over-the-phone cognitive behavioral therapy as well as those who met with a therapist face to face experience improvements in their mental condition but with some differences. Whereas more of those who received telephone therapy stayed with therapy, a higher proportion of them had experienced the relapse of depression after six months. Those who participated in face-to-face therapy had a slightly lower rate of staying in therapy but they were more resilient (Watzke, Haller, Steinmann et al. 2017; Basu 2020). What important is, that teletherapy might significantly increase access to mental health care and the apps may draw people's attention to other opportunities of help-seeking.

\section{CONCLUSIONS: TOWARDS THE DECONSTRUCTIONS OF BINARY CATEGORIES OF MENTAL HEALTH AND MENTAL DISORDERS IN THE FRAMES OF CRITICAL SITUATION}

In the context of the above analyses, we can ask a set of questions about the construction of the categories of mental health and mental disorder in the entirely new circumstances (comparing to the world that the contemporary individuals know). What can be the prospective consequences of the pandemic for the understanding of the categories of 'mental health' and 'mental disorder'? What kind of emotional reactions (taken into consideration when one's mental health is discussed) are adequate in the situation of pandemic and social isolation resulting from it? Is there only one scenario of adequate and adaptive reactions? How can we know which of the possible reactions are adequate and which of them are not? In such an extraordinary situation as a global pandemic wide range of human reactions are possible. Even those that indicate strong distress are understandable in their context. The individual who is rezoning with his or her environment and who is sensitive to what is going on in the outside world move toward the "health" pole on the 'health'-'disease' continuum. Moreover, in most comments on the present situation, the negative consequences of social distancing are pointed out. However, these consequences are much more painful for extraverts than for introverts. The concept of 'mental health' was mostly based on the image of an extravert, easy-going and relaxed person. The distance attitude, shyness and to some extend introversion (even though in psychological theories it is conceptualized as a dimension of personality) have been medicalized and labeled with the diagnostic category of 'social anxiety disorder' (Scott 2006; Conrad 2007). The extraverts seemed to be better adjusted to socio-cultural requirements from the pre-pandemic times, whereas the introverts, assuming that their anxiety caused by the outside conditions is not so intensive that it disorganizes their functioning, seem to be better adjusted to the circumstances that force the social isolation. The lack of the necessity of involuntary, mostly superficial social interactions and the chance to function in one's own 
pace can reduce the stress and the prospective anxiety and depressive symptoms in introverts.

To sum up the whole consideration presented in this paper we can put forward a thesis that the current situation forces the global community not only to face the concrete mental health problems and design the appropriate solutions but also inspires the discussion on the assumptions underlying the concepts of mental health and mental disorders as well.

FUNDING: This research received no external funding.

CONFLICT OF INTEREST: The author declares no conflict of interest.

\section{REFERENCES}

Alexander, Jeffrey. 2004. “Toward a Theory of Cultural Trauma." in Cultural Trauma and Collective Identity, edited by J. C. Alexander, R. Eyerman, B. Giesen et al. Berkeley: University of California Press.

Anxiety and Depression Association of America, 2020. "Facts \& Statistics." Retrieved March 31, 2020 (https://adaa.org/about-adaa/press-room/facts-statistics).

Bai, Ya Mei, Chai-Chend Lin, Ching-Mo Chue et al. 2004. "Survey of stress reactions among health care workers with the SARS outbreak." Psychiatric Services 55(9):1055-1057. doi:10.1176/appi.ps.55.9.1055.

Basu, Tanya. 2020. "The coronavirus pandemic is a game changer for mental health care." Humans and Technology, 20 March 2020, https://www.technologyreview. com/s/615390/coronavirus-online-therapy-mental-health-app-teletherapy/, access: 31, March 2020.

Chua, Siew E., Vinci Cheung, Charlton Cheung et al. 2004. "Psychological effects of the SARS outbreak in Hong Kong on high-risk health care workers.” Canadian Journal of Psychiatry 49(6): 391-393. doi:10.1177/070674370404900609

Conrad, Peter. 2007. The Medicalization of Society: On the Transformation of Human Conditions into Treatable Disorders. Baltimore: The Johns Hopkins University Press MD.

Dong, Lu, Jennifer Bouey. 2020. "Public mental health crisis during COVID-19 pandemic, China.” Emerging Infectious Diseases 26(7). DOI: 10.3201/eid2607.200407.

Fowler, Damian. 2020. "Unemployment during coronavirus: The psychology of job loss.” BBC Worklife, 28 March 2020, https://www.bbc.com/worklife/article/20200327-unemployment-during-coronavirus-the-psychology-of-job-loss, access: 31 March 2020.

Jenkins, Sharon Rae,_Stephanie Baird. 2002. "Secondary traumatic stress and vicarious trauma: A validational study.” Journal of Traumatic Stress 15(5): 423-432. https:// 
doi.org/10.1023/A:1020193526843

Lai, Jianbo, Simeng Ma, Ying Wang et al. 2019. "Factors Associated With Mental Health Outcomes Among Health Care Workers Exposed to Coronavirus Disease 2019.” JAMA Network Open 3(3): e203976. doi:10.1001/jamanetworkopen.2020.3976

Lee, Antoinette M., Josephine GWS Wong, Grainne M. McAlonan et al. 2007. "Stress and psychological distress among SARS survivors 1 year after the outbreak." The Canadian Journal of Psychiatry 52(4): 233-240. doi:10.1177/070674370705200405

Lee, Matthew. 2020. "Coronavirus fears show how 'model minority' Asian Americans become the 'yellow peril'." THINK, Opinion, Analysis, Esseys, March 9. Retrieved March 30, 2020 (https://www.nbcnews.com/think/opinion/coronavirus-fears-show-how-model-minority-asian-americans-become-yellow-ncna1151671).

Łoza, Bartosz. 2020. „Psychiatra o kwarantannie: Załamanie emocji dopiero przed nami (interview: Piotr Górski).” Rzeczpospolita, 24.03.2020, https://www. rp.pl/Koronawirus-SARS-CoV-2/303249907-Psychiatra-o-kwarantannie-Zalamanie-emocji-dopiero-przed-nami.html?fbclid=IwAR3wl4Q4lqcv5oIzigZxBwpN-GyM4upYKfBRwNiA9pdLGI7-_LimkJNmgIc, access: 31 March 2020. Mahdawi, Arwa. 2020. "For some people, social distancing means being trapped indoors with an abuser.” The Guardian, 21 March. Retrieved March 31, 2020 (https:// www.theguardian.com/commentisfree/2020/mar/21/coronavirus-domestic-violence-week-in-patriarchy?fbclid=IwAR0G-ks51Be2tG8EUYbTLnAsHEzJ2AYpOWfx8sBr7fya50ojSOmZjPj_608).

Mak, Ivan Wing Chit, Chung Ming Chu , Pey Chyou Pan. 2009. "Long-term psychiatric morbidities among SARS survivors." General Hospital Psychiatry 31(4): 318326. DOI:10.1016/j.genhosppsych.2009.03.001.

Maunder, Robert, Jonathan Hunter, Leslie Vincent et al. 2003. "The immediate psychological and occupational impact of the 2003 SARS outbreak in a teaching hospital." CMAJ 168(10): 1245-1251. Retrieved March 31, 2020 (https://www.ncbi.nlm. nih.gov/pmc/articles/PMC154178/).

Moskalewicz, Jacek, Andrzej Kiejna and Bogdan Wojtyniak. 2012. „Kondycja psychiczna mieszkańców Polski." Raport z badań Epidemiologia zaburzeń psychiatrycznych i dostęp do psychiatrycznej opieki zdrowotnej - EZOP Polska. Warsaw: Instytut Psychiatrii i Neurologii.

Person, Bobbie, Francisco Sy, Kelly Holton et al. 2004. "Fear and Stigma: The Epidemic within the SARS Outbreak.” Emerging Infectious Diseases 10(2): 358-363.

Pinnock, Sarah. 2017. "Prologue: Death as Atrocity." in Facing Death: Confronting Morality in the Holocaust and Ourselves, edited by S. K. Pinock. Washington: University of Washington Press.

Scott, Susie. 2026. "The Medicalisation of Shyness: From Social Misfits to Social Fitness." Sociology of Health \& Illness 28(2): 133-153. DOI: 10.1111/j.14679566.2006.00485.x

Selye, Hans. 1976. Stress in Health and Disease. Boston-London: Butterworth.

Shultz, James M., Janice L. Cooper, Florence Baingana et al. 2016. "The role of fear-related behaviors in the 2013-2016 West Africa Ebola virus disease outbreak.” Cur- 
rent Psychiatry Reports 18(104). https://doi.org/10.1007/s11920-016-0741-y Sztompka, Piotr. 2002. Socjologia. Analiza społeczeństwa. Cracow: Znak Publishing. Watzke, Brigit, Elisa Haller, Maya Steinmann et al. 2017. "Effectiveness and cost-effectiveness of telephone-based cognitive-behavioural therapy in primary care: study protocol of TIDe - telephone intervention for depression." BMC Psychiatry 17 (263). https://doi.org/10.1186/s12888-017-1429-5

World Health Organization Regional Office for Europe. 2011. “Impact of economic crisis on mental health." Geneva: WHO.

World Health Organization. 2001. "Mental Health Report 2001. Mental Health: new understanding, new hope.” Geneva: WHO. Retrieved March 31, 2020 (https:// www.who.int/whr/2001/en/whr01_en.pdf?ua=1).

World Health Organization. 2005. "Guidelines for Gender-based Violence Interventions in Humanitarian Settings." Geneva: Inter-Agency Standing Committee. Retrieved March 31, 2020 (https://www.who.int/hac/techguidance/pht/GBVGuidelines08.28.05.pdf).

World Health Organization. 2014. "Health for the world's adolescents." Geneva: WHO. Retrieved March 31, 2020 (http://www.who.int/mediacentre/news/releases/2014/focus-adolescent-health/en/).

World Health Organization. 2019. "Novel coronavirus (2019-nCoV): strategic preparedness and response plan.” Feb 3, 2020. Retrieved March 31, 2020 (https://www. who.int/docs/default-source/coronaviruse/srp-04022020.pdf).

World Health Organization. 2020. “Depression, key facts.” Retrieved March 31, 2020 (https://www.who.int/en/news-room/fact-sheets/detail/depression).

\section{BIOGRAPHICAL NOTE}

Monika Frąckowiak-Sochańska, $\mathrm{PhD}$ is an assistant professor at the Faculty of Sociology, Adam Mickiewicz University in Poznań, Poland. She is interested in the sociology of mental health, gender studies, sociology of values, and social work.

OPEN ACCESS: This article is distributed under the terms of the Creative Commons Attribution Non-commercial License (CC BY-NC 4.0) which permits any non-commercial use, and reproduction in any medium, provided the original author(s) and source are credited. 
